\title{
SEMIOTIKA UMPASA BAHASA BATAK TOBA: PENDEKATAN ROLAND BARTHES
}

\author{
${ }^{1}$ Putri Sion Sinaga; ${ }^{2}$ Bambang Djunaidi; ${ }^{3}$ Irma Diani
}

Program Studi Pendidikan Bahasa Indonesia Jurusan Pendidikan Bahasa dan Seni

Abstrak

\section{Korespondensi: putrisionsinaga@gmail.com}

Tujuan penelitian ini adalah untuk mendeskripsikan makna denotasi dan konotasi umpasa bahasa Batak Toba dengan menggunakan pendekatan Roland Barthes. Metode yang digunakan dalam penelitian ini adalah metode deskriptif. Data yang dikumpulkan berasal dari tiga sumber buku kumpulan umpasa dan adat Batak Toba. Teknik pengumpulan data penelitian ini adalah teknik dokumentasi, sedangkan data dianalisis menggunakan pendekatan Roland Barthes. Berdasarkan hasil tabel klasifikasi penelitian dan pembahasan tentang makna denotasi dan konotasi, penulis menemukan dari 55 data umpasa, 46 di antaranya mengandung konotasi. Hasil penelitian menunjukkan bahwa umpasa dapat diklasifikasikan berdasarkan jenisnya yaitu (1) pernikahan (2) kelahiran (3) kematian (4) memasuki rumah baru, dan (5) baptisan kudus yang terdiri dari makna denotasi dan konotasi. Tanda-tanda denotasi terletak di bagian sampiran yang menjadi petanda denotasi, sedangkan tanda konotasi terletak di bagian isi. Petanda denotasi dan petanda konotasi pada dua bagian tersebut menghasilkan hubungan semiotik yang menjadi sebuah pesan dalam setiap jenis umpasa. Tanda-tanda denotasi dan konotasi yang ditemukan pada; (1) umpasa pernikahan di antaranya berupa tumbuh-tumbuhan seperti andor halumpang dan padang togu, hewan seperti ular dari, sungai seperti sungai Sihoru-horu, bukit dan desa seperti Bukit Sitapongan dan tanda yang lainnya yang berhubungan dengan adat dan kehidupan masyarakat Batak Toba; (2) umpasa memasuki rumah baru di antaranya berupa tumbuh-tumbuhan seperti pakis dan andor, sungai seperti sungai Siboru-boru, buah-buahan seperti buah labu; (3) umpasa kelahiran di antaranya berupa hewan seperti burung kutilang, tumbuhan seperti pohon beringin dan tambinsu; (4) umpasa kematian di antaranya berupa keindahan alam butan Sipoholon, benda langit yaitu matahari dan bulan, tumbuhan seperti daun bahompu, serta Bukit Simalungun dan Bukit Simamora; (5) pohon tambinsu dan pohon Nangka serta benda langit seperti bulan. Berdasarkan hasil penelitian dapat disimpulkan bahwa umpasa bahasa Batak Toba mengandung makna denotasi dan konotasi sesuai dengan petanda denotasi dan petanda konotasi yang menghasilkan hubungan semiotik yang menjadi sebuah pesan dalam setiap jenis umpasa.

Kata Kunci: semiotika, denotasi, konotasi, umpasa

\section{Abstract}

This study aimed to described the meaning of denotation and connotation of the Toba Batak language used by Roland Barthes approach.The method of this study used a descriptive method. The data collected from three sources of umpasa collection books and Toba Batak customs. The research data collect technique was documentation technique, while the data were analyzed using the Roland Barthes 
approach. Based on the results of the research classification table and discussion of the meaning of denotation and connotation, the researchers found from 55 data bases, 46 of which contain connotations. The results showed that umpasa could be classified based on its type, namely (1) marriage (2) birth (3) death (4) entering a new home, and (5) holy baptism consisting of denotation and connotation meaning. The denotation signs are located on the side of the denotation markers, while the connotation signs are located on the contents. Denotation markers and connotation markers in the two parts produce a semiotic relationship that becomes a message in each type of umpasa. Denotation and connotation signs found on; (1) marriage includes plants such as andor halumpang and togu fields, animals such as snakes from, rivers such as Sihoru-horu river, hills and villages such as Bukit Sitapongan and other signs related to the customs and life of the Toba Bataknese; (2) when entering a new house including plants such as ferns and andor, rivers such as the Sihoru-horu river, fruits such as pumpkins; (3) birth outcomes include animals such as finches, plants such as banyan trees and tambinsu; (4) the death stories include the natural beauty of the Sipoholon forest, celestial objects, namely the sun and moon, plants such as hahompu leaves, and Simalungun Hill and Simamora Hill; (5) tambinsu and jackfruit trees and sky objects such as the moon. Based on the results of the study it could be concluded that the Batak Toba language umpakan contains denotation and connotation meaning in accordance with denotation and connotation markers that produce semiotic relationships which become a message in each type of umpasa.

Keywords: semiotics, denotation, connotation, umpasa

\section{PENDAHULUAN}

Semiotika adalah ilmu tentang tanda. Istilah tersebut berasal dari kata Yunani semeion yang artinya "tanda". Tanda dapat kita temukan di mana-mana, juga seperti kata yang merupakan sebuah tanda, gerak-gerik isyarat, lampu lalu lintas, bendera, timbangan, hal tersebut merupakan sebuah tanda. Peirce (1978) dalam (Sudjiman dan Zoest, 1996: 1) menambahkan bahwa tanpa sebuah tanda kita tidak dapat berkomunikasi.

Dalam dunia semiotika dikutip dari buku Jafar et al., (2017: 1) dikenal dua tokoh utama semiotika yakni Ferdinand de Saussure (1857-1913) dan Charles Sanders Peirce (1839-1914). Saussure menyebut semiotika dengan nama teori yang lebih umum yaitu semiologi, sedangkan Peirce menyebutnya semiotika. Beberapa tokoh semiotik lainnya yaitu Charles Williams Morris (1901-1979) yang mengembangkan behaviourist semiotics, tokoh semiotik lainnya yang turut mengembangkan teori-teori semiotik modern yakni Roland Barthes (1915-1980), Algirdas Greimas (1917-1992), Yuri Lotman (1922-1993), Christian Metz (193-1993), Umberco Eco (1932), dan Julia Kristeva (1941). Lebih lanjut mengenai jenis semiotik, antara lain semiotik analitik, diskriptif, faunal zoomsemiotic, kultural naratif, natural, normatif, sosial, dan struktural (Jafar et al., 2017: 2).

Semiotika menurut Roland Barthes memfokuskan teori pada makna konotasi dan makna denotasi. Makna konotasi adalah makna kedua atau secara kultural yang akan menghadirkan kode-kode makna tanda yang bersifat implisit. Makna konotasi secara struktural merupakan makna yang keberadaannya terletak pada dua sistem perbedaan yang diandaikan memungkinkan teks bekerja seperti sebuah permainan. Makna denotasi adalah makna bahasa menghadirkan kode-kode sosial yang bersifat eksplisit (Jafar et al., 2017: 129). 
Suku batak merupakan salah satu suku terbesar di Indonesia selain suku Jawa. Suku batak erat kaitannya dengan istilah Daliban Na Tolu. Daliban Na Tolu ini diibaratkan seperti tiga tungku masak di dapur tempat menjerangkan periuk. Oleh sebab itulah, adat Batak menjadikan istilah tersebut sebagai penopang dalam kehidupan, yaitu: (1) pihak semarga (in group); (2) pihak penerima istri (wife receiving party); serta (3) pihak yang memberi istri (giving party). (Siahaan, 1982: 35 dalam Armawy, 2008).

Daliban $\mathrm{Na}$ Tolu tersebut dapat dijelaskan dengan tiga pengertian yaitu yang pertama Hula-bula merupakan sekelompok orang yang posisinya lebih tinggi atau "di atas", pihak ini merupakan pihak yang berasal dari keluarga marga istri. Bentuk penghormatan terhadap kelompok hula-hula dalam masyarakat Batak Toba dikenal sebutan "Somba marbula-bula" yang berarti harus hormat kepada keluarga marga pihak istri agar memperoleh keselamatan dan kesejahteraan. Unsur kedua merupakan Dongan Tubu artinya sekelompok orang yang posisinya sama atau "sejajar", yaitu: teman/saudara semarga tetap harus akrab dan kompak, sehingga dalam masyarakat Batak Toba dikenal sebutan "manat mardongan tubu", artinya menjaga hubungan persaudaraan agar terhindar dari perseteruan. Unsur kekerabatan yang terakhir adalah dalam bahasa Batak Toba disebut Boru, yaitu kelompok penerima istri, yang dalam suatu acara adat posisinya adalah sebagai "pekerja", atau "parbobas" sehingga dalam masyarakat Batak Toba dikenal sebutan "elek marboru" yang artinya agar memperhatikan dan mengayomi kelompok penerima marga istri karena pihak "boru" itulah yang akan bekerja atau marbobas saat acara adat batak berlangsung.

Suku batak ini merupakan kumpulan dari berbagai suku-suku di Sumatera Utara. Beberapa suku yang termasuk di antaranya yaitu Batak Toba, Batak Simalungun, Batak Pakpak, Batak Karo, dan Batak Angkola/Batak Mandailing. Suku adat Batak Toba terkhusus yang bermukim di daerah Tapanuli Utara yang letak geografisnya meliputi:

a. di sebelah utara berbatasan dengan wilayah Bahasa Batak Karo (Kabupaten Karo) dan wilayah Bahasa Simalungun (Kabupaten Simalungun);

b. di sebelah timur berbatasan dengan wilayah Bahasa Melayu (Kabupaten Asahan/Labuhan Batu);

c. di sebelah selatan berbatasan dengan wilayah Bahasa Angkola/Mandailing (Kabupaten Tapanuli Tengah/Selatan);

d. di sebelah barat berbatasan dengan wilayah Bahasa Dairi/Pakpak (Kabupaten Dairi). Wilayah Bahasa Batak Toba di bagi atas empat daerah yaitu Pulau Samosir, Toba Holbung, Silindung/Pahae dan Humbang Hasundutan (Sitanggang, 1996: 26).

Umpasa adalah pantun batak yang ada di setiap sub suku batak yang ada di Indonesia. Namun penulis menganalisis umpasa yang ada pada adat Batak Toba. Bentuk umpasa termasuk dalam jenis puisi lama berbentuk karmina yang terdiri dari dua baris. Baris pertama disebut sampiran dan baris kedua sebagai isi. Sampiran dan isi memiliki hubungan makna selain untuk menyamakan bunyi akhir (rima) saja. Oleh sebab itulah tanda yang terdapat dalam umpasa terletak pada bagian sampiran, sehingga menghasilkan makna. Umpasa dituturkan dalam setiap upacara adat Batak Toba. Dikutip dari Sitanggang, (1996: 46-48) menyatakan bahwa adat Batak Toba merupakan persatupaduan kebudayaan rohani dan kemasyarakatan yang meliputi berbagai aspek kehidupan seperti hukum, kesusilaan, keagamaan, sistem kekerabatan, bahasa, seni, dan teknologi. Wujud umpasa termasuk dalam kebudayaan abstrak yang memuat sikap, kepercayaan, pandangan hidup atau sesuatu yang tak terasa digelarkan saat upacara tradisional. Oleh sebab itulah 
umpasa merupakan saluran adat yang diyakini masyarakat pemiliknya sebagai pengendali peri kehidupannya sehari-hari, berisikan pengharapan, permohonan, nasihat petunjuk hidup dan berkat bagi mereka yang akan diberikan sebuah umpasa Batak Toba. Umpasa yang akan dibahas pada penelitian ini yaitu umpasa pada saat acara adat pernikahan, adat kelahiran, adat kematian, memasuki rumah baru dan baptisan kudus dilaksanakan oleh suatu keluarga/kumpulan masyarakat batak.

Penelitian terdahulu tentang umpasa dan teori Roland Barthes pernah dilakukan oleh Mawaddah (2015) berjudul "Analisis Semiotika Buka Pintu Pada Upacara Pernikahan Masyarakat Desa Teluk Rampah Kecamatan Torgamba Kabupaten Labubanbatu Selatan" yang membahas mengenai makna denotasi dan konotasi yang terdapat dalam pantun Buka Pintu, dan mitos (pesan) yang terkandung pada pantun, serta mengenai alasan penggunaan pantun Buka Pintu oleh masyarakat Mandailing Desa Teluk Rampah Kecamatan Torgamba Kabupaten Labuhanbatu Selatan pada upacara pernikahan mereka, dan penelitian oleh Amsari (2018) berjudul "Pantun Orang Muda pada Masyarakat Melayu: Kajian Semiotik" membahas mengenai analisis struktural dan analisis makna denotasi dan konotasi Pantun Orang Muda Masyarakat Melayu.

Penelitian lainnya berjudul "Semiotika Umpasa Dalam Perkawinan Batak Toba" oleh Pasaribu (2017) yang memperoleh adanya makna semiotik pada umpasa dalam perkawinan Batak Toba yaitu semiotik ikon, indeks dan semiotik simbol. Penelitian tentang umpasa Batak juga sudah pernah dilakukan oleh Simamora (2017) yang berjudul "Umpasa Sebagai Cerminan Nilai Budaya Batak Toba: Kajian Antropolinguistik.” dengan hasil bahwa makna umpasa adat pernikahan Batak Toba ada tiga, yaitu makna perbandingan, makna menasehati, dan makna harapan.

Beberapa penelitian terdahulu tersebut meneliti umpasa dengan masalah yang berbeda, memang tidak dipungkiri bahwa banyak hal yang bisa dianalisis dari sebuah umpasa bahasa Batak Toba. Namun, penelitian umpasa dengan kajian teori Roland Barthes dan pada acara adat Batak Toba yang lain belum penulis temukan. Oleh karena itu, penulis tertarik dan berusaha untuk menyusun dan menganalisis penelitian tentang umpasa bahasa Batak Toba kajian teori Roland Barthes dan tidak hanya terfokus pada upacara adat perkawinan atau pernikahan saja, tetapi juga pada acara adat batak seperti kelahiran, kematian dan acara lainnya dilihat dari analisis semiotika makna denotasi, konotasi dan pesan yang terkandung di dalam umpasa, karena dengan dianalisisnya umpasa selain pernikahan, umpasa acara adat lainnya akan kembali diingat, dilestarikan dan dikembangkan oleh pembaca khususnya masyarakat Batak Toba.

Rumusan masalah dalam penelitian ini adalah bagaimana makna denotasi dan makna konotasi dalam umpasa adat Batak Toba. Contoh umpasa tersebut seperti berikut.

Sabat-sahat ni solu sahat ma tu bontean

Sai sahat ma tu parborasan, sabat hita tu panggabean

(Sampailah sampan sampai ke tempat berlabuh)

(Sampailah kita menuju kebahagiaan dan kesejahteraan)

Semiotika pada umpasa tersebut terdapat pada kata solu dan bontean. Solu berarti sampan yang bermakna rumah tangga atau sebuah keluarga sedangkan bontean bermakna puncak kebahagiaan dan tujuan hidup keluarga. Umpasa ini biasanya digunakan pada saat acara adat pernikahan adat Batak Toba dilaksanakan dan yang diucapkan oleh keluarga pengantin atau kerabat bahkan tamu undangan yang hadir pada saat adat berlangsung ketika hendak memberikan ulos kepada pengantin. ulos diberikan kepada kedua 
pengantin. Pemberian ulos tersebut dilakukan oleh setiap pihak keluarga laki-laki, keluarga pihak perempuan, kumpulan marga-marga dari kedua pihak pengantin dan keluarga yang berada dalam satu wilayah tempat tinggal pengantin laki-laki dan perempuan. Maksud dari umpasa di atas adalah hendaklah kita semua termasuk pengantin menuju dan mendapatkan kebahagiaan dan kesejahteraan dalam hidup ditengah-tengah keluarga layaknya sebuah perahu yang menuju tujuannya di tempat berlabuhnya perahu.

Bintang na rumiris tu ombun na sumorop

Anak pe antong riris boru pe torop

(Bintang yang berderet, ke embun yang banyak dan berjejer)

(Anak laki-laki pun berderet, anak perempuan pun banyak)

Tanda pada umpasa di atas terdapat pada kata bintang na rumiris dan ombun sumorop. Bintang na rumiris berarti banyaknya bintang dan embun yang berjejer dan banyak. Maksud dari umpasa di atas adalah agar memiliki banyak anak laki-laki dan perempuan yang berjejer dan banyak layaknya sebuah bintang dan ombun (embun). Umpasa ini dapat digunakan saat acara kelahiran atau baptisan kudus adat Batak Toba dilaksanakan yang dapat diucapkan oleh keluarga yang melaksanakan acara atau kerabat bahkan tamu undangan yang hadir pada saat adat berlangsung ketika hendak memberikan ulos dan mandok hata (ucapan selamat) kepada keluarga yang beracara. Simbol lain dalam umpasa Batak Toba, seperti andor halumpang yang berarti tumbuhan merambat halumpang, bulu 'bambu', bulung 'daun', andubur 'tekukur', dan sebagainya.

Tak hanya itu, umpasa adalah sastra lisan yang hidup dan masih berkembang bahkan selalu dipakai dalam berbagai aspek kehidupan masyarakat Batak Toba juga memiliki arti dan makna pada setiap adatnya, sebagai harapan atau doa restu, sebagai ayat hukum adat, sebagai nasihat atau petuah, bentuk kepercayaan dan keyakinan dan bisa menjadi alat untuk menyindir atau memojokkan jalan pikiran atau sifat seseorang.

\section{METODE}

Metode penelitian merupakan prosedur, alat maupun teknik yang dipilih dalam untuk melaksanakan penelitian saat mengumpulkan data (Djajasudarma, 2010: 4). Penelitian ini menggunakan metode deskriptif. Data-data yang disajikan dalam penelitian ini berupa umpasa tertulis yang berupa jenis, makna konotasi dan denotasi yang terdapat dalam umpasa bahasa Batak Toba dengan cara mencari atau mengumpulkan data, mengklasifikasi data dan selanjutnya menganalisis data untuk mengetahui makna denotasi, konotasi dan pesan umpasa bahasa Batak Toba.

Sumber data dalam penelitian ini adalah umpasa dari tiga buku yang berasal dari wilayah Sumatera Utara yaitu:

1) Judul Buku

: Jambar Hata

Pengarang

: T.M. Sihombing

Penerbit

: CV. Tulus Jaya

Tahun terbit

: 1989

Jumlah Halaman

: 334 halaman

2) Judul Buku

Pengarang

: Umpasa dan Umpama Dalam Bahasa Batak Toba

Penerbit

: Drs. Richard Sinaga

Tahun Terbit

: Dian Utama Jakarta

: 2016 


\author{
Jumlah Halaman \\ 3) Judul Buku \\ Pengarang \\ Penerbit
}

Tahun terbit

Jumlah Halaman
: 144 halaman

: Tradisi Umpasa Suku Batak Toba

: S.R.H Sitanggang

: Pusat Pembinaan dan Pengembangan Bahasa

Departemen Pendidikan dan Kebudayaan, Jakarta

: 1996

: 192 halaman

Data dalam penelitian ini adalah umpasa dalam adat pernikahan, kelahiran, kematian, memasuki rumah baru dan penyerahan anak dalam acara adat bahasa Batak Toba yang berjumlah 55 umpasa.

\begin{tabular}{|c|c|c|}
\hline No. & Jenis Umpasa & Jumlah \\
\hline 1. & Memasuki rumah baru & 10 \\
\hline 2. & Pernikahan & 25 \\
\hline 3. & Kelahiran & 7 \\
\hline 4. & Kematian & 7 \\
\hline 5. & Baptisan Kudus & 6 \\
\hline & Jumlah & 55 \\
\hline
\end{tabular}

Teknik yang digunakan untuk pengumpulan data adalah teknik dokumentasi. Teknik dokumentasi digunakan karena data berasal dari kumpulan buku umpasa bahasa Batak Toba.

Langkah-langkah memperoleh data melalui teknik dokumentasi yaitu, mengumpulkan dan mengelompokkan umpasa berdasarkan jenisnya, menghitung jumlah setiap umpasa dalam adat batak dan membaginya dalam jenis acara adat Batak Toba. Langkah-langkah analisis data yang digunakan dalam penelitian ini adalah sebagai berikut.

a. Membaca umpasa bahasa Batak Toba secara berulang-ulang dengan cara membaca untuk menemukan arti dan makna umpasa, membaca untuk menentukan penanda yang diikuti petandanya serta membaca untuk menemukan pesan yang terkandung dalam umpasa.

b. Menterjemahkan arti dan makna umpasa ke dalam bahasa Indonesia

c. Menentukan penanda denotasi, petanda konotasi dan pesan umpasa.

d. Memvalidasi hasil analisis data kepada penutur bahasa batak, ahli bahasa batak dan tokoh adat Batak Toba.

e. Mengelompokkan dan menjelaskan hasil analisis umpasa yaitu makna denotasi dan konotasi berdasarkan teori Roland Barthes berdasarkan jenisnya, yaitu umpasa pernikahan, umpasa kelahiran, umpasa kematian, umpasa memasuki rumah baru, dan umpasa baptisan kudus.

Hasil analisis data terlebih dahulu divalidasi untuk dipastikan kebenaran dan ketepatannya. Langkah-langkah yang dilakukan oleh penulis menggunakan triangulasi sebagai berikut.

1. Pengecekan data oleh pemerhati kebudayaan adat batak Bengkulu, oleh Bapak P. Sidabalok berumur 59 tahun, terhitung sejak 20 Maret-4 April 2020.

2. Pengecekan data oleh pembicara adat batak Bengkulu, oleh Bapak Japan Sinaga berumur 66 tahun, terhitung sejak 23 Maret-4 April 2020.

3. Pengecekan data oleh tokoh adat Batak oleh Bapak Jasmin Sinaga berumur 60 tahun, terhitung sejak 23 Maret-4 April 2020. (Laporan terlampir pada balaman 90-97) 
Pengecekan hasil analisis data sudah dilakukan oleh dosen bidang linguistik FKIP Universitas Bengkulu, Ibu Ngudining Rahayu, M.Hum pada 16 Juli 2020.

\section{HASIL DAN PEMBAHASAN}

Hasil penelitian ini adalah penjelasan mengenai makna denotasi dan konotasi umpasa yang dijelaskan dengan beberapa bentuk umpasa.

1. Umpasa Pernikahan

Andor halumpang ma togu-togu ni lombu

Saur matua ma hamu patogu-togu pahompu

(Tumbuhan merambat halumpang yang mengikat seekor lembu)

(Panjang umurlah kalian sampai menuntun/membimbing cucu)

Tanda denotasi pada umpasa ini terletak di bagian sampiran yaitu tumbuhan bernama andor halumpang dan berupa binatang lembu. Makna leksikal yang terkandung pada tumbuhan andor halumpang berarti jenis tumbuhan yang memiliki akar merambat dan binatang tersebut berarti seekor hewan sapi/lembu. Tak hanya itu, dibalik makna tersebut, dalam kebudayaan batak ada makna tambahan di dalamnya yaitu andor halumpang merupakan jenis akar tumbuhan yang ditemukan pada kayu di hutan belantara tua, orang batak pada zaman dulu menggunakan andor halumpang untuk mengikat hewan sapi karena akar ini sangatlah kuat dan lombu yang dimaksud adalah seekor lembu/sapi yang umurnya sudah tua yang mampu diikat dengan sebuah tali yang merambat dari andor halumpang tadi. Oleh sebab itulah ditemukan semiotik melalui hubungan antara petanda denotasi dan petanda konotasi antara bagian sampiran dan isi yang akan menghasilkan pesan bahwa melalui umpasa ini hendaklah keluarga yang baru menikah hidup seperti andor halumpang yang fungsinya untuk mengikat lembu/sapi, mengiring-iring sapi yang sudah tua tersebut kemanapun ia berjalan. Begitulah pula harapan agar kelak pasangan baru ini panjang umur, tua bersama dan mengiring para cucu, layaknya tumbuhan halumpang yang mampu mengikat lembu tua hingga panjang umur sampai membimbing/menuntun cucu nantinya.

2. Umpasa Kelahiran

Dangka ni hariara tanggo pinangait-aithon

Sai horas ma bamu antong sai tongka panabit-nabiton

(Cabang pohon beringin kuat meskipun ditarik-tarik)

(Sehatlah kalian dan jauhlah dari sakit penyakit)

Tanda denotasi umpasa ini terletak di bagian sampiran berupa tumbuhan beringin yang bermakna pohon yang batangnya besar dan kuat, cabangnya pun kuat dan tidak mudah patah, sesuai dengan makna sebenarnya. Tak hanya itu, dibalik makna tersebut, dalam kebudayaan batak ada makna tambahan di dalamnya yaitu petanda konotasi bahwa pohon beringin mempunyai kekuatan dari setiap bagiannya termasuk ranting pohonnya yang tidak mudah putus dan kuat meskipun ditarik-tarik. Melalui petanda denotasi dan petanda konotasi tersebut, menghasilkan hubungan semiotik yang juga pesan dalam umpasa bahwa layaknya pohon beringin meskipun di tarik-tarik, ia tetap kuat dan tahan. Oleh sebab itulah pula harapannya agar keluarga yang baru saja diberikan seorang anak untuk tetap sehat sejahtera dan dijauhkan dari sakit penyakit layaknya pohon beringin yang kuat dan tahan terhadap apapun. Tidak hanya orang tua, tetapi anak yang baru lahir tersebut diberikan kesehatan, anak yang baru lahir layaknya dangka ni hariara, cabangnya yang kuat dan tidak mudah patah seperti maksud dari baris isi sebagai petanda konotasi. Harapan 
dalam umpasa agar sehat sejahteralah orang tua dan anak yang baru lahir tersebut serta dijauhkan dari sakit penyakit yang menghampiri.

3. Umpasa Kematian

Hau di Gunungtua dangkana mardagul-dagul

Tibu ma dilehon Tuhanta di hamu tua, jala tibu hamu diapul-apul

(Kayu di Gunung Tua rantingnya berangkai-rangkai) dihibur)

(Segeralah diberikan Tuhan kepada kalian berkat dan segeralah pula kalian

Tanda denotasi umpasa ini terletak di bagian sampiran berupa hau (kayu) dan dangka (ranting). Makna leksikal pada tanda tersebut adalah hau atau kayu merupakan bagian batang pohon yang keras, sedangkam dangka atau ranting adalah bagian cabang pohon yang kecil-kecil. Umpasa ini digunakan pada saat adat batak kematian berlangsung. Pesan yang hendak disampaikan umpasa ini bahwa Tuhan akan memberikan dengan segera berkat dan penghiburan kepada keluarga yang sedang berduka.

4. Umpasa Memasuki Rumah Baru

Tubu ma tandiang ditopi aek Sibarabara

Sai gok ma jolma diginjang gok pinahan ma tombara

(Tumbuhlah pakis di tepi sungai Sibarabara)

(Banyaklah orang di atas, banyak ternak dikandang)

Tanda denotasi umpasa ini terletak di bagian sampiran berupa tumbuhan pakis dan sungai Sibarabara. Pakis adalah tumbuhan yang membiak dengan spora, biji atau tunasnya muncul dari pangkal pohonnya, sedangkan Aek Sibarabara adalah sungai yang ada di daerah Sumatera Utara. Tak hanya itu, dibalik makna tersebut, dalam kehidupan dan kebudayaan batak terdapat makna tambahan di dalamnya yaitu Pakis merupakan tumbuhan yang dikenal sebagai tanaman hias yang dapat mempercantik dan memperindah rumah ketika banyak ditumbuhi tanaman ini. Pakis yang banyak tumbuh di tepi sungai Sibarabara layaknya gok ma jolma diginjang gok pinahan ma tombar, yang artinya banyaklah penghuni rumah di dalam rumah baru dan hewan. Umpasa ini digunakan pada saat adat memasuki rumah baru berlangsung, berisi pesan berupa harapan agar banyaklah penghuninya, banyak anak cucu dan ternaknya.

5. Umpasa Baptisan Kudus

Horbo ni sibuluan manjampal di balian

Sai dapot ma di hamu angka na niluluan jala sai tiur nang pansarian

(Kerbau yang dibersihkan makan rumput di ladang)

(Semoga dapatlah apa yang kalian cari dan bersinar dalam pencaharian)

Tanda denotasi umpasa ini terletak di bagian sampiran berupa binatang horbo (kerbau) dan ladang yang bermakna kerbau merupakan binatang yang biasa diternakkan untuk diambil dagingnya atau untuk dipekerjakan, rupanya seperti lembu dan agak besar, tanduknya panjang, sedangkan ladang merupakan tempat yang luas yang diusahakan karena mengandung sumber daya alam. Umpasa ini digunakan pada saat adat batak baptisan kudus berlangsung, serta berisi harapan agar keluarga yang baru saja anaknya dibaptis, diberkati langkahnya apapun yang dicari dan diberkati mata pencaharian.

Hasil penelitian yang diperoleh juga berdasarkan teori Ferdinand de Saussure (1857-1913) yang merumuskan teori semotika mengenai tanda bahasa yaitu petanda dan penanda dan setelah itu dikembangkan kembali oleh Roland Barthes (1968) yang 
menjelaskan serta mengembangkan teori semiotika menjadi dua tingkatan tanda yaitu denotasi dan konotasi, dengan acuan peta tanda Barthes berikut.

\begin{tabular}{|c|c|}
\hline $\begin{array}{c}\text { 1. Signifier } \\
\text { (penanda) }\end{array}$ & \multicolumn{1}{c|}{$\begin{array}{c}\text { 2.Signified } \\
\text { (petanda) }\end{array}$} \\
\hline 3. Denotative sign (tanda denotatif) & \\
& \\
4. CONNOTATIVE SIGNIFIER \\
(PENANDA KONOTATIF)
\end{tabular}

Tabel: Peta Tanda Roland Barthes (Cobley \& Jansz, 1999 dalam Sobur, 2016: 69)

Peta Barthes (1999) tersebut menunjukkan bahwa tanda denotatif (3) terdiri atas penanda (1) dan petanda (2). Namun pada saat yang bersamaan tanda denotatif juga adalah penanda konotatif (4). Menentukan makna konotasi berdasarkan peta tanda Barthes (1999, dalam Sobur 2001) sesuai dengan penjelasan bahwa tanda denotatif (3) terdiri atas penanda (1) dan petanda (2). Namun pada saat yang bersamaan tanda denotatif juga adalah penanda konotatif (4). Oleh sebab itulah untuk menentukan penanda konotatif harus berdasarkan tanda denotatif (denotasi) sebelumnya. Namun dalam konsep Barthes, tanda konotatif tidak sekadar memiliki makna tambahan namun juga mengandung kedua bagian tanda denotatif yang melandasi keberadaannya.

Barthes (dalam Jafar et al., 2017: 127-128) mengatakan bahwa konotasi merupakan makna-makna yang tidak ada, baik dalam kamus atau dalam tata bahasa yang digunakan untuk menulis teks. Penanda konotasi dibangun dari tanda-tanda dari sistem denotasi. Biasanya beberapa tanda denotasi dapat dikelompokkan bersama untuk membentuk satu konotator tunggal; sedang petanda konotasi berciri sekaligus umum, global dan tersebar. Petanda ini juga bisa disebut fragmen ideologi. Petanda ini memiliki komunikasi yang sangat dekat dengan budaya, pengetahuan dan sejarah (Barthes, 1968 : 129-130).

Tak hanya itu, makna konotasi juga merupakan sebuah kata yang dipengaruhi dan ditentukan oleh lingkungan tekstual dan lingkungan budaya (Sumardjo \& Saini, 1994: 126 dalam Sobur 2016: 266). Oleh sebab itulah dalam analisis, makna konotasi umpasa ini juga ditentukan dan dipengaruhi oleh lingkungan budaya adat Batak Toba berdasarkan narasumber penutur Bahasa Batak, ahli Bahasa Batak Toba dan raja parhata Bahasa Batak Toba, dan rangkaian adat batak yang berlaku sampai saat ini.

Makna denotasi dan konotasi dalam umpasa dapat dijelaskan dengan penjelasan berikut.

Sahat-sahat ni solu sahat ma tu Tigaras

Sahat ma hamu leleng mangolu gabe jala horas 
(Sampailah sampan, sampailah hingga ke Tigaras)

(Sampailah kalian sampai panjang umur dan hidup damai sejahtera) (P/TS19)

Penanda denotasi umpasa ini adalah sampan adalah sebuah perahu kecil dan Tigaras juga merupakan desa tempat berdagang di tepi Danau Toba. Sedangkan petanda konotasi menjelaskan bahwa sampan apabila terus dikayuh/dikemudikan secara bersamasama akan sampailah ia dengan cepat ke tujuan, yaitu ke Desa Tigaras.

Layaknya keluarga apabila terus diusahakan dengan baik dan bersama-sama maka sampailah pula keluarga sampai ke tujuan hidup yang bahagia dan sejahtera. Menurut raja parhata batak dan pemerhati kebudayaan batak di Bengkulu, berpendapat bahwa setiap umpasa digunakan sebagai bentuk permohonan, harapan, dan doa bagi pihak yang menerima umpasa pada saat acara adat batak berlangsung. Umpasa ini berisi harapan agar sekeluarga hidup terus berusaha secara bersama dan panjang umur serta sehat sejahtera. Penjelasan mengenai makna yang terkandung pada tanda-tanda konotatif, juga ditentukan dan dipengaruhi oleh lingkungan budaya adat Batak Toba berdasarkan narasumber penutur Bahasa Batak, ahli Bahasa Batak Toba dan raja parhata Bahasa Batak Toba serta rangkaian adat batak yang berlaku.

\section{PENUTUP}

Berdasarkan hasil analisis hasil penelitian dan pembahasan mengenai semiotika umpasa bahasa Batak Toba dan yang sesuai dengan rumusan masalah, dapat disimpulkan bahwa:

1. Makna denotasi umpasa pernikahan, umpasa memasuki rumah baru, umpasa kelahiran, umpasa kematian dan umpasa baptisan kudus mengandung tanda-tanda denotasi yang dilihat dari penanda denotasi pada umpasa sehingga menghasilkan makna berdasarkan pengertian dalam Kamus Besar Bahasa Indonesia dan penutur bahasa batak. Tandatanda denotasi yang ditemukan terletak di bagian sampiran atau baris pertama di setiap jenis umpasa. Tanda-tanda denotasi pada umpasa pernikahan diantaranya berupa tumbuhan andor halumpang, padang togu, pohon Simartolu, tumbuban lata, salaon, Arirang, sirih dan gambir, tumbuban padang togu, dan rumput sirumata, binatang seperti ular dari, berupa alam sekitar seperti sungai Sihoru-horu, desa Pinamparan, juga berupa ornamen batak seperti ogung oloan. Tanda-tanda denotasi yang ditemukan pada umpasa memasuki rumah baru yaitu diantaranya berupa tumbuhan seperti tumbuhan simarlasuna, tumbuban pakis, tumbuhan salaon, berupa keadaan alam sekitar seperti sungai sihoru-horu, ladang. Tanda-tanda denotasi yang ditemukan pada umpasa kelahiran yaitu diantaranya berupa binatang seperti berutu, dan burung tekukur serta berupa tumbuhan yaitu pohon beringin dan pohon tambinsu. Tanda-tanda denotasi yang ditemukan pada umpasa kematian yaitu diantaranya berupa tumbuhan seprti pohon tambinsu, berupa binatang seperti burung kutilang, serta keadaan alam sekitar seperti sampan.

2. Makna konotasi yang dihasilkan dari umpasa pernikahan, umpasa memasuki rumah baru, umpasa kelahiran, umpasa kematian dan umpasa baptisan kudus berasal dari makna denotasi sebelumnya yang sesuai dengan teori peta tanda Roland Barthes. Dari petanda denotasi sesuai dengan kesimpulan sebelumnya akan dijelaskan kembali makna lebih luas pada petanda konotasi berdasarkan pengertian, pengetahuan, pengalaman penutur bahasa batak, tokoh adat batak, dan raja parbata batak toba di Bengkulu dan adat kebudayaan batak Toba yang berlaku. Tanda-tanda konotasi yang ditemukan terletak di bagian isi atau baris ke dua setiap jenis umpasa. Tanda-tanda konotasi umpasa pernikahan diantaranya berupa tumbuhan andor halumpang, padang 
togu, pohon Simartolu, tumbuban lata, salaon, sirih dan gambir, tumbuban padang togu, binatang seperti ular dari, berupa alam sekitar seperti sungai Sihoru-horu, desa Pinamparan. Tandatanda konotasi yang ditemukan pada umpasa memasuki rumah baru yaitu diantaranya berupa tumbuhan seperti tumbuhan pakis, tumbuhan salaon, berupa keadaan alam sekitar seperti sungai siboru-horu. Tanda-tanda konotasi yang ditemukan pada umpasa kelahiran yaitu diantaranya berupa binatang seperti berutu, dan burung tekukur serta berupa tumbuhan yaitu pohon beringin dan pohon tambinsu. Tanda-tanda konotasi yang ditemukan pada umpasa kematian yaitu diantaranya berupa tumbuhan seprti pohon tambinsu, berupa binatang seperti burung kutilang, serta keadaan alam sekitar seperti sampan. Tanda-tanda konotasi ini menjadi petanda konotasi yang sesuai dengan bagian isi atau baris ke dua yang merupakan makna dalam kehidupan manusia terutama masyarakat batak, seperti makna sebuah harapan, doa, permohonan dan pandangan hidup. Seperti jenis tumbuhan andor halumpang yang mengikat lembu dengan kuat, seperti itulah maksud di baris ke dua sebagai petanda konotasi yaitu keluarga pengantin mengikat dengan kuat layaknya tumbuhan dan binatang tersebut. Namun tidak semua data umpasa mengandung makna konotasi. Setiap jenis umpasa digunakan pada jenis acara adat batak diberlangsungkan, sehingga tidak sembarang orang batak yang mampu mengucapkan dan menggunakannya.

Penelitian ini membahas tentang semiotika umpasa Bahasa Batak Toba pada berbagai acara adat batak, yaitu umpasa pernikahan, umpasa memasuki rumah baru, umpasa kelahiran, umpasa kematian dan umpasa baptisan kudus. Penelitian ini hanya berfokus pada makna menurut teori peta tanda Roland Barthes, serta dukungan pesan secara umum yang terkandung dalam umpasa. Penulis menyadari bahwa hasil penelitian ini belum sempurna dan penulis berharap akan ada penelitian selanjutnya yang akan membahas umpasa acara adat batak lainnya dengan teori yang sama bahkan melanjutkan penelitian ini secara mendalam dengan kajian yang berbeda. Penelitian ini juga hanya meneliti mengenai makna denotasi dan konotasi umpasa dan pesan secara umum dari umpasa yang terkandung, penulis berharap penelitian selanjutnya dapat meneliti umpasa sampai kepada mitos/pesan secara mendalam.

\section{DAFTAR RUJUKAN}

Armawy, Armaidy. (2008). Kearifan Lokal Batak Toba Dalihan Na Tolu Dan Good Governance Dalam Birokrasi Publik. Jurnal. Volume 18, No. 2. File:///C:/Users/Me/Downloads/3522-29054-1-PB.Pdf. Diakses pada 26 Juli 2020.

Barthes, R. (1968). Elemen-Elemen Semiologi. Ardiansyah. (2017). Basabasi. Yogyakarta.

Djajasudarma, Fatimah. (2010). Metode Linguistik: Ancangan Metode Penelitian dan Kajian. Bandung: Refika Aditama

Jafar, Nila dan Khairussibyan. (2017). Semiotika Teori, Metode dan Penerapannya dalam Penelitian Sastra. Yogyakarta: Deepublish

Kurniawan. (2001). Semiologi Roland Barthes. IndonesiaTera, dari https://books.google.co.id/books?id=fxhA1o7t4i0C\&dg=konotasi + dan + meta bahasasource $=$ gbs_navlinks_s.

Rahardi, Kunjana. (2020). On Emblematic Meanings of Traditional Medicinal Herbs: Local 
Wisdom Values in the Perspective of Culture-Specific Ecopragmatics. Arbitrer. Vol. 7 No. 1. http://arbitrer.fib.unand.ac.id/index.php/arbitrer/article/view/187. Diakses pada 2 Agustus 2020.

Saussure, Ferdiinand De. (1988) Pengantar Linguistik Umum. Gadjah Mada University Press

Sihombing, T. (1989). Jambar Hata. CV. Tulus Jaya

Sinaga, R. (2016). Umpasa, Umpama dan Ungkapan Dalam Babasa Batak Toba. Jakarta: Dian Utama

Sitanggang. (1996). Tradisi Umpasa Suku Batak Toba. Jakarta: Pusat Pembinaan dan Pengembangan Bahasa

Sobur, Alex. (2016). Semiotika Komunikasi. Bandung: PT Remaja Rosdakarya 